\title{
A dêixis: fenômeno referencial ou enunciativo?
}

\begin{abstract}
Alena Ciulla*
Resumo: O estado da arte revela uma diferença fundamental nos estudos sobre a dêixis, que ora é tratada como fenômeno referencial, ora como fenômeno enunciativo. Do ponto de vista enunciativo, a dêixis é enfatizada pela sua característica autorreferencial, crucial para a organização do ato de referir. Sob a visada referencial, essa discussão traz consequências não apenas para as questões do texto, na abordagem da referenciação, mas também para as tipologias de dêiticos e anafóricos. O intuito aqui não é o de descartar perspectivas, mas o de evidenciar critérios mais sólidos para a análise textual.
\end{abstract}

Palavras-chave: Autorreferência. Dêixis. Enunciação. Referência.

Abstract: The state of the art reveals a fundamental difference in studies on deixis, since it is treated at times as a referential phenomenon and at times as an enunciative phenomenon. From the point of view of the enunciation studies, deixis is emphasized as token-reflexive, crucial for the organization of the reference act. Under the referential approach, this discussion has consequences not only for the questions of the text, as in the referenciation approach, but also for the deitics and anaphorics typologies. The aim here is not to discard perspectives, but to highlight solid criteria to textual analysis.

Keywords: Token-Reflexive. Deixis. Enunciation. Reference.

Résumé: L'état de l'art révèle une différence fondamentale dans les études sur la deixis, qui est traitée parfois comme un phénomène référentiel, parfois comme un phénomène énonciatif. Du point de vue énonciatif, la deixis est soulignée par son caractère autoréférentielle, essentiel pour l'organisation de l'acte de référence. Sous la visée référentielle, cette discussion a des conséquences non seulement pour les questions du texte, comme sous l'approche de la référenciation, mais aussi pour les typologies déictiques et anaphoriques. Il ne s'agit pas ici d'écarter les perspectives, mais de mettre en évidence des critères plus robustes pour une analyse textuelle.

Mots-clés: Auto-Référence.Deixis. Énonciation. Référence.

\section{Introdução}

\footnotetext{
* Professora adjunta do Departamento de Letras Clássicas e Vernáculas e do Programa de Pós-graduação em Letras, no Instituto de Letras da UFRGS, atua na linha de pesquisa Análises textuais, enunciativas e discursivas. Membro do Grupo Protexto (CNPq/UFC). https://orcid.org/0000-0002-0710-9397
}

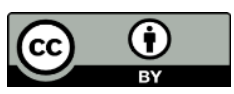


Os estudos sobre a dêixis são numerosos e, no entanto, ainda há muita controvérsia sobre o assunto. Segundo Kleiber:

Os dêiticos estão, como sabemos, na origem de duas importantes evoluções em linguística: a revogação do dogma saussuriano língua-discurso, com o rumo direcionado para os domínios da enunciação, e o advento da pragmática, pelo alargamento da semântica vericondicional de frases que contêm dêiticos (KLEIBER, 2013, p. 2) $)^{1}$.

O estudo da dêixis está na origem das viradas da pragmática e da linguística, como indiretamente afirma Kleiber, não por acaso. Sendo indissociável do fenômeno enunciativo, pois depende e é instaurada pelo eu que enuncia, a dêixis ao mesmo tempo se relaciona com o mundo que é referido: quando falamos, falamos sempre para alguém de algo no mundo. Ou seja, a dêixis está implicada na enunciação, como recurso linguístico, e no enunciado, sendo o que possibilita estabelecer a referência dos enunciados. Esse seria um enfoque enunciativo para a questão. No entanto, a explicação sobre o funcionamento da linguagem e sobre a relação da linguagem com o mundo não é unívoca e depende da perspectiva epistemológica que se adota. Daí uma das grandes divergências que fizeram e fazem florescer tantos estudos sobre o assunto.

Outra vertente de tratamento da dêixis vem de uma tradição de estudos, com base na etimologia da palavra do grego antigo deíknymi, que significa a ação de mostrar - e mostrar, relacionando-se ao ato de referir objetos, tanto em se tratando de expressão linguística, quanto de sinalização corporal. A importância do traço de ostensão, frequentemente atribuído à dêixis, está associada até mesmo ao mito da origem da linguagem: teria a linguagem humana partido de uma primeira tentativa de apontar para os objetos ou teria partido de uma necessidade de nomeá-los? Não se tem indícios claros que possam comprovar uma ou outra hipótese, mas, para Bühler (1934), a tendência é a de que as duas operações tenham sido concomitantes. Concordamos com a hipótese de Bühler, pois sob a perspectiva que defendemos, desde Ciulla (2008), nomear implica em

\footnotetext{
${ }^{1}$ A tradução desta citação e de todas as outras citações de títulos e obras, cujas referências indicam publicação em línguas estrangeiras, que não o português, são de responsabilidade da autora deste artigo. 
conceitualizar, e apontar, de certa maneira, também implica em uma conceitualização, já que, conforme postulou Quine (1960), nada garante que ao referir um objeto ele seja (re)conhecido pelos falantes. Isso porque a referência depende de uma construção de sentidos que é particular para cada situação, para cada par ou grupo de falantes. É na enunciação, sob certas condições, que incluem o eu-aqui-agora, relacionada à dêixis, além de questões culturais e sócio-históricos, através da intersubjetividade e interação entre os falantes, que os sentidos vão sendo negociados e atribuídos - e somente assim, sob essas condições, a referência é realizada. Essa discussão é complexa e abrange aspectos sobre referência, significação e sentido que não são a temática deste artigo e apenas tangencialmente fazem parte da discussão. Contudo, mostra que desde as investigações mais remotas sobre a linguagem, é levantada a questão sobre o quanto e como a dêixis está relacionado à referência.

O conceito de dêixis mais recorrente é o que inclui não apenas a sua relação com a origo que identifica o locutor, mas também o próprio referente visado pela referência em questão, conforme se pode observar no Manual of deixis, organizado por Jungbluth e Da Milano (2015), em que se reúnem diversos artigos, frutos de pesquisas feitas no mundo todo, sobre dêixis em diversas línguas. De modo geral, esse enfoque, que designo aqui como referencial, trata de responder a duas principais questões, quais sejam a que se refere a expressão indicial e como a expressão permite especificar seu referente.

Em nossa pesquisa atual ${ }^{2}$, levando-se em consideração um refinamento sobre o pensamento de Benveniste, para investigar a noção de referência e de enunciação, deparamo-nos com a problemática que permeia grande parte da explicação sobre o funcionamento e definição da dêixis e da anáfora, elementos centrais nos processos de referenciação. Assim, mergulhamos em um estudo sobre o funcionamento enunciativo da referência, com o intuito de responder, num primeiro passo, à questão de como as línguas referem e quais mecanismos ou dispositivos as línguas dispõem para referir.

\footnotetext{
${ }^{2}$ Desde 2017, viemos desenvolvendo um projeto, registrado pela Comissão de Pesquisa da Universidade Federal do Rio Grande do Sul, sob o n. 32484, em que estudamos a referência e a enunciação, sob um ponto de vista proporcionado por Émile Benveniste.
} 
Umas das primeiras constatações a que chegamos é a de que se, por um lado, muitos trabalhos ressaltam a importância dos estudos enunciativos de Benveniste no que diz respeito à subjetividade, que coloca o homem como centro da linguagem, para os estudos do texto, a nosso ver, o interesse estaria mais voltado para a investigação sobre a expressão da subjetividade, isto é, para as categorias de pessoa e seu papel e funcionamento nos enunciados.

Assim, afunilando o nosso olhar para o que Benveniste diz a respeito da categoria de pessoa, que se associa indubitavelmente à dêixis, observamos o quanto abordagens diferentes propiciam diferentes tipos de explicação ou análise.

Em Ciulla (2019), por exemplo, apresentamos um estudo sobre a definição de dêixis em Benveniste e em Bühler, mostrando os diferentes aspectos, nem sempre congruentes, que são levados em consideração para as tipologias dêiticas. Conforme se observa em Cavalcante (2000) e Ciulla (2002), e em trabalhos mais recentes, como Martins (2019) e Ciulla e Martins (2017), tais classificações de dêiticos mostram-se bastante problemáticas, muitas vezes confundindo-se com a anáfora, por não apresentarem critérios homogêneos para a diversidade de tipos que são produzidos na linguagem. Um dos principais motivos para esta incongruência é, acreditamos, aqui, o fato de que não é feita a distinção, sugerida pelo título deste trabalho, sobre a definição da dêixis como fenômeno referencial ou enunciativo.

Por oportuno, lembramos o trabalho de Kleiber (2013) intitulado Dêixis, embrayeurs, token-reflexivos, símbolos indexicais, etc.: como os definir?, em que o autor propõe também tratar o fenômeno sob dois pontos de vista, que ele nomeia de A e B. No grupo A, estariam abrigadas as abordagens que salientam o lugar e o objeto de referência, já o B abrigaria as abordagens que privilegiam o modo de referência. Kleiber afirma que:

(...) apesar de pontos de convergência, as duas vias definitórias não são equivalentes e, em segundo lugar, são as abordagens B, em termos de funcionamento referencial, que são as mais adequadas. Caminho feito, seremos levados a denunciar ou retificar esta ou aquela afirmação sobre este ou aquele tipo de expressão, o objetivo final deste trabalho sendo o de chegar a uma melhor apropriação e compreensão de sua especificidade semântico- 
referencial. A tese defendida, finalmente, é a de um token-reflexividade em termos de espaço-temporalidade (KLEIBER, 2013, p. 2).

De nossa parte, pela via do estudo da enunciação em Benveniste, estamos ainda nos apropriando de uma das abordagens que se enquadrariam como B, para Kleiber. E, por isso, não confirmamos nossa adesão completa às conclusões do autor. Ao mesmo tempo, Kleiber, no trecho acima citado, corrobora nossa aposta inicial, de que o estudo do funcionamento referencial - o que implica em estudar o aspecto enunciativo da referência, portanto - pode ser frutífero e adequado para uma melhor compreensão do fenômeno da dêixis.

Assim, nosso intuito não é o de descartar uma ou outra abordagem, mas o de aprofundar o estudo sobre questões que são levantadas pelos diferentes tratamentos do fenômeno. E também o de levar em conta esses diferentes tratamentos, no momento de fundamentar as análises e as classificações.

Propomos, então, considerar a dêixis em três eixos: o primeiro diz respeito à definição de dêixis que aparece na obra de Benveniste, circunscrita à relação de remissão do enunciado à instância enunciativa; o segundo, sobre a noção de dêixis como um processo de sinalização de referentes em situações comunicativas, na linha proposta por Bühler (1934), mas que inclui a maior parte dos autores que se dedicaram aos estudos classificatórios de dêixis e também dos que lançam mão de tais tipologias em suas análises de processos referenciais; e, por fim, o terceiro, sobre uma proposta de análise enunciativa dos sistemas temporais, os quais funcionam como um tipo de embrayeur textual.

Com este estudo, além de se abrir mais uma porta para a investigação de critérios mais homogêneos para as classificações em tipos dêiticos, ao observarmos vários modos de conceituar a dêixis, salientados pelos diferentes autores, evidencia-se a amplitude da importância deste fenômeno para a linguagem.

Um primeiro eixo de observação, então, seria o da dêixis na enunciação - que é como Benveniste trata dessa questão. 


\section{A dêixis como fenômeno enunciativo}

Benveniste (2005) parte de uma distinção entre a categoria de pessoa e os nomes, destacando uma propriedade fundamental dos pronomes pessoais eu e tu na organização referencial dos signos linguísticos. Se a cada instância de emprego de um nome a referência é constante, apta a permanecer virtual (significado lexical) ou atualizar-se num objeto singular (numa situação enunciativa concreta), por outro lado,

(...) as instâncias de emprego de eu não constituem uma classe de referência, uma vez que não há "objeto" definível como eu ao qual se possam remeter identicamente essas instâncias. Cada eu tem a sua referência própria e corresponde cada vez a um ser único, proposto como tal (BENVENISTE 2005, p. 278).

Para o autor, então, eu somente poderia ser definido em termos de locução, não em termos de objeto, como é do caso do signo nominal. E, por isso, sublinha o seguinte ponto: "eu só pode ser identificado pela instância de discurso que o contém e somente por aí. Não tem valor a não ser na instância na qual é produzido” (BENVENISTE, 2005, p.278-279).

E enfatiza a função necessária de remissão à instância de discurso, desempenhada por esses elementos:

\footnotetext{
Essa referência constante e necessária à instância de discurso constitui o traço que une a eu/tu uma série de indicadores que pertencem, pela sua forma e pelas aptidões combinatórias, a classes diferentes - uns pronomes, outros advérbios, outros ainda locuções adverbiais.

São, em primeiro lugar, os demonstrativos: este, etc. na medida em que se organizam correlativamente com os indicadores de pessoa, como no lat. hic/iste (BENVENISTE, 2005, p. 279).
}

Vislumbra-se, nesse trecho, aquilo que norteia o princípio definidor da dêixis, para Benveniste, que é a remissão à instância de discurso que contém eu. Além disso, para o autor, a dêixis é o traço que une eu/tu a outros indicadores, como os 
demonstrativos este/esse, por remeter à instância de discurso que contém eu. Porém, adverte Benveniste, com relação a esses outros indicadores:

Há aqui um traço novo e distintivo dessa série: é a identificação do objeto por um indicador de ostensão concomitante com a instância de discurso que contém o indicador de pessoa: esse será o objeto designado por ostensão simultânea à presente instância de discurso, a referência implícita na forma (por exemplo, hic oposto a iste) associando-o a eu, a tu (BENVENISTE, 2005, p. 279).

Também os advérbios aqui e agora são dimensionados pelo autor, em sua relação com eu, porém numa classe distinta dos demonstrativos, na medida em que "delimitam a instância espacial e temporal coextensiva e contemporânea da presente instância de discurso que contém eu" (BENVENISTE, 2005, p.279). Nessa série, são incluídos também termos que procedem da mesma relação, como hoje, ontem, amanhã, em três dias, etc.

Não se pode negar, contudo, a implicação do referente na afirmação sobre o processo instaurado por eu, como fica evidente nas palavras do autor: "Há, pois, nesse processo uma dupla instância conjugada: instância de eu como referente, e instância do discurso contendo eu, como referido" (BENVENISTE, 2005, p.278-279). Ainda assim, para a noção de dêixis, a ênfase dada é a característica desses elementos como indicadores da presente instância de discurso, como se observa, novamente, a seguir:

Não adianta nada definir esses termos e os demonstrativos em geral pela dêixis, como se costuma fazer, se não se acrescenta que a dêixis é contemporânea da instância de discurso que contém o indicador de pessoa; dessa referência o demonstrativo tira o seu caráter cada vez único e particular, que é a unidade da instância de discurso à qual se refere (BENVENISTE, 2005, p. 279-280).

A relação visada, em primeiro lugar, portanto, é a do indicador de pessoalidade e seu tempo e espaço com a instância de discurso em questão, renovada e única a cada vez que se enuncia. O traço de ostensão não é, para Benveniste, o que define a dêixis, ainda que se possa dizer, em muitos casos, que é concomitante à dêixis. Para o autor, o apontamento para objetos é uma função dos signos lexicais, sendo que a dêixis diz respeito somente à relação do que é dito com as condições pessoais, temporais e 
espaciais do que é dito e é, então, um fenômeno de ancoragem dos enunciados em relação às condições de enunciação.

Assim, a característica que distingue um elemento dêitico de outros elementos da língua, para Benveniste, é a sua capacidade autorreferencial, que é a capacidade de ser reflexivo da instância de discurso que contém eu. O que faz a deiticidade de um signo, para o autor, não é a sua propriedade de apontar para objetos, mas a de apontar para a própria instância de discurso, permitindo a comunicação intersubjetiva. O seu papel, então, não é o de fazer referência à realidade objetiva, mas fornecer o instrumento de uma conversão: a da língua em discurso.

E o que significa "converter a língua em discurso"? Apesar de muito repetida, essa expressão nem sempre é revestida da importância que tem. Converter a língua em discurso é o exercer da subjetividade, é a possibilidade de se tornar sujeito na língua e pela língua, é a possibilidade da própria linguagem, o que é propiciado pelos elementos autorreferenciais, mais especificamente pela categoria de pessoa, que existe em todas as línguas conhecidas. Sem esse recurso,

\begin{abstract}
(...) se cada locutor, para exprimir o sentimento que tem de sua subjetividade irredutível, dispusesse de um "indicativo" distinto (no sentido em que cada estação radiofônica possui o seu "indicativo" próprio), haveria praticamente tantas línguas quantos indivíduos e a comunicação se tornaria estritamente impossível. A linguagem previne esse perigo, instituindo um signo único, mas móvel, eu, que pode ser assumido por todo locutor, com a condição de que ele, cada vez, só remeta à instância do seu próprio discurso. Esse signo está, pois, ligado ao exercício da linguagem e declara o locutor como tal. É essa propriedade que fundamenta o discurso individual, em que cada locutor assume por sua conta a linguagem inteira (BENVENISTE, 2005, p. 281).
\end{abstract}

No trecho acima, fica evidente, a nosso ver, a importância da dêixis, vista em seu aspecto de autorreferencialidade, para a linguagem. A abordagem "dura” de Benveniste para a dêixis se justifica por que somente esses elementos podem desempenhar essa função e ela é essencial ao exercício da linguagem.

Por outro lado, a referência aos objetos no mundo depende dessa sinalização dada pelos dêiticos. Para Benveniste: 
Um enunciado pessoal finito se constitui, pois, sobre um plano duplo: emprega a função denominativa da linguagem para as referências de objeto que esta estabelece como signos lexicais distintivos, e organiza essas referências de objeto com a ajuda de indicadores autorreferenciais correspondentes a cada uma das classes formais que o idioma reconhece (BENVENISTE, 2005, p. 282).

Esse “duplo plano" proposto por Benveniste pode ser visto como uma configuração de dois âmbitos da referência: o da referência, propriamente dita, a objetos, e que está relacionada a enunciados, e o da autorreferência, que diz respeito a um processo enunciativo, aos dispositivos que as línguas oferecem para ancorar os enunciados e possibilitar a comunicação intersubjetiva.

Nessa visada, portanto, os dêiticos são somente definidos como tal, com a condição de cumprir um papel como organizadores reflexivos da instância de discurso, ou seja, com a condição da autorreferencialidade. Todas as outras relações de sinalização, de objetos no mundo, dar-se-iam em outro plano e seriam classificadas a partir de critérios de ostensão, como a identificação e especificação do referente.

O segundo eixo, apresentado a seguir, diz respeito à definição da dêixis, privilegiando o seu sentido de sinalizar referentes.

\section{A dêixis e sua definição a partir do traço de ostensão}

Bühler (1934) advoga o poder da representação da linguagem, ao apresentar e mostrar - que são dois significados contidos na palavra em alemão darstellen, conforme o autor. Este aspecto do pensamento de Bühler é o que funda a noção de campo dêitico, pois, para ele, a linguagem mostra, ao representar. É enfatizada, então, a ideia da representação dêitica por ostensão. Além disso, observamos, assim, a configuração da dêixis como fundamental na linguagem, sob um outro aspecto, que não apenas o de fundar o centro de referência da instância do discurso, mas o de representar, mostrando.

Antes de seguir, é interessante contextualizar sua obra, pois Bühler, que era psicólogo e escreveu seus estudos sobre a linguagem sob a perspectiva da percepção 
humana, influenciou fortemente o círculo de Viena. Daí compreendemos as origens de sua análise da linguagem como ferramenta na comunicação: a linguagem, para o autor, seria um organon que permite a alguém transmitir a um outro, alguma coisa, sobre as coisas. Outro aspecto é que, para Bühler (1934), interessa como fenômeno de linguagem aquilo que acontece na comunicação cotidiana, em contextos comunicativos e nas diferentes funções que o que é dito pode realizar no interior da interlocução.

Por esta perspectiva, então, é que Bühler (1934) propõe dois campos para as ciências da linguagem: o campo simbólico e o campo dêitico. A especificidade dos dêiticos estaria, para Bühler, no que diz respeito ao fato de que diferentemente dos signos $^{3}$ do campo simbólico, convencionados por um código (como os sistemas da matemática, das cores, ou do domínio musical), os signos dêiticos dependeriam da percepção da situação comunicativa. Assim, o traço comum dos dêiticos é que não receberiam o preenchimento de sua significação e precisão no campo simbólico, mas os receberiam, caso a caso, no campo dêitico da linguagem.

A significação dos signos linguísticos, então, por essa visão, é derivada da sua relação com o campo a que pertence; uma relação que, no caso dos signos dêiticos, é fundada na percepção. O fundamento perceptivo dos signos dêiticos se apresenta, de acordo com Bühler, porque o campo dêitico seria suscetível ao aparelho sensorial humano, permitindo que o preenchimento de significação dos termos dêiticos se realizasse. Bühler insiste: para o seu funcionamento, os termos dêiticos têm necessidade do que se oferece no campo dêitico ao olho e ao ouvido, independentemente de que se trate do olho "exterior" ou "interior".

E aqui um ponto fundamental para compreender a função representacional da linguagem bühleriana: a de que o campo dêitico contem auxiliares dêiticos sensíveis, sem os quais esse funcionamento dos signos dêiticos seria inexplicável.

\footnotetext{
3 Conforme já dito em Ciulla (2019), embora conhecedor do Cours de Linguistique Général, que ele próprio menciona em Sprachtheorie, a noção de signo, em Bühler não é a mesma proposta por Saussure. Bühler não considera o signo como uma associação de significante e significado, mas apenas como realização acústica, estabelecendo uma sinonímia entre signo linguístico e a mensagem propriamente dita. Para o autor, a mensagem, ou o signo linguístico, mantém uma relação tríplice: com as coisas (que seriam objetos da linguagem), com o emissor da mensagem e com o receptor da mensagem.
} 
Nas palavras do autor: "Não há signo sonoro dêitico que possa dispensar o gesto ou um fio condutor sensível equivalente ao gesto, ou, finalmente, o estabelecimento de uma convenção de orientação" (BÜHLER, 1934, p. 192).

Ao dizer "aquele ali", explica o autor, somos quase sempre obrigados a acompanhar esta expressão com um apontamento da coisa visada.

Mais dois tipos de auxiliares dêiticos são identificados por Bühler: a origem espacial do som e o timbre da voz. O auxiliar origem espacial do som é o que permite identificar pelo olhar a pessoa que fala, de onde vem o som. O auxiliar timbre da voz permite realizar uma identificação da pessoa pela memória acústica que temos da sua voz.

Para Bühler, os dêiticos são modos de apresentar e de mostrar de uma maneira sensível, são signos "exclusivamente ou principalmente destinados a funcionar como placas sinalizadoras para o olhar" e o preenchimento de sua significação depende, por consequência, da percepção visual ou auditiva. Este preenchimento se realizaria como uma atividade orientada pelo lugar em que o locutor ou o ouvinte ocupa no campo de percepção. Vê-se, então, que a definição de dêixis está relacionada, para Bühler, com a percepção do objeto referido, ainda que seja considerada a origo do falante em questão.

Conforme o autor, há apenas um campo dêitico na linguagem, mas os modos da dêixis são variados. Bühler (1934) identifica um primeiro caso, que seria a demonstração (ou apontamento) ad oculos, a qual pode ser interpretada como pelos olhos ou que faz apelo ao que pode ser percebido visivelmente.

Este tipo pode operar de maneira anafórica, no discurso distanciado da situação de comunicação. Incluir a anáfora como um caso de dêixis se justifica, em sua abordagem, pois que as anáforas fazem apelo ao olhar: quando num texto, por exemplo, há “É disso que eu falava!", é preciso direcionar o olhar para a porção de texto em que se pode encontrar "disso".

Também um outro modo, o chamado por Bühler de am Phantasma se inclui no campo dêitico, pois, ainda que exija um deslocamento imaginário, a operação é de visualizar uma cena e, a partir de nosso centro de percepção, ser capaz de seguir as instruções dêiticas dadas pelas expressões. Um exemplo deste modo é o que acontece 
quando alguém dá indicações de como chegar a um endereço e diz "Quando chegar na esquina de tal rua, dobre à direita...”.

Observamos que os signos dêiticos, para o autor, atuam em modos diferentes, o que significa dizer que os tipos diferentes não são revelados pelas expressões dêiticas em si, mas pelo modo como operam no campo dêitico. Assim, é importante frisar que em termos bühlerianos, não haveria um dêitico ad oculos ou am Phantasma, a priori, em uma situação comunicativa, mas signos que preenchem seu significado numa situação comunicativa ao modo ad oculos ou am Phantasma.

Como se vê, os tipos dêiticos sugeridos por Bühler (1934) fundam-se em critérios de percepção sensorial dos objetos referidos na situação comunicativa. A dêixis, neste caso, está associada à sinalização - e é assim que Bühler a define - a referentes no mundo.

Por fim, apresentamos o terceiro eixo de observação, ainda apenas delineado, sobre uma proposta de análise de planos enunciativos dos textos.

\section{Análise enunciativa dos textos, a partir do tempo}

De um ponto de vista da referenciação, em que também tratamos dêiticos e anafóricos como processos referenciais, em análises textuais, vimos afirmando que esses elementos desempenham um importante papel de coerência no texto, em mecanismos de progressão e retomada que auxiliam e orientam a constituição do sentido, conforme demonstrado em vários trabalhos anteriores.

Neste trabalho, cogitamos outra perspectiva de análise, que diz respeito à questão do tempo na língua e que se relaciona à marca de pessoa - e, portanto, à dêixis benvenisteana. Esta é uma sugestão de análise textual (arrisco dizer que uma das raras) oferecida por Benveniste em sua obra.

Para começar, Benveniste (2005) argumenta sobre como a organização dos tempos dos verbos depende de princípios menos evidentes e mais complexos do que pretendem os paradigmas dos manuais de gramática. $\mathrm{O}$ autor demonstra como se pode 
perceber dois sistemas distintos e complementares, observando-se os tempos do verbo francês, que seriam os planos de enunciação da história e o do discurso. A identificação desses planos pode fornecer um indicativo de diferentes tipos de texto.

A enunciação histórica estaria associada à narrativa, ao acontecimento e ao passado. Conforme o autor:

Trata-se da apresentação dos fatos sobrevindos a um certo momento do tempo, sem nenhuma intervenção do locutor da narrativa. Para que possam ser registrados como se tendo produzido, esses fatos devem pertencer ao passado (...) A intenção histórica constitui realmente uma das grandes funções da língua: imprime-lhe a sua temporalidade específica, cujas marcas formais devemos agora assinalar (Benveniste, 2005, p. 262).

Observamos que quando Benveniste (2005) menciona "sem nenhuma intervenção do locutor" não pretende propor uma ausência de subjetividade - até porque a teoria toda de Benveniste supõe uma subjetividade inseparável da linguagem. Benveniste se refere, nesta questão, ao fato de que não são deixadas marcas formais de subjetividade. Justamente é a situação, como normalmente se observa nos livros de história, em que um narrador omnisciente "relata fatos”, numa espécie de assunção de uma realidade objetiva.

Em contraponto à enunciação histórica, Benveniste apresenta o plano do discurso. O discurso deve ser entendido, aqui,

(...) na sua mais ampla extensão: toda enunciação que suponha um locutor e um ouvinte e, no primeiro, a intenção de influenciar, de algum modo, o outro. (...) enfim, todos os gêneros nos quais alguém se dirige a alguém, se enuncia como locutor e organiza aquilo que diz na categoria da pessoa (Benveniste, 2005, p. 267).

A identificação desses dois planos enunciativos não significa que num texto não possa haver uma sobreposição de planos, conforme Benveniste assinala:

Na prática, passa-se de um ao outro instantaneamente. Cada vez que no seio de uma narrativa histórica aparece um discurso, quando o historiador, por exemplo, reproduz as palavras de um personagem ou intervém, ele próprio, para julgar os acontecimentos referidos, se passa a outro sistema temporal, o 
do discurso. O próprio da linguagem consiste em permitir essas transferências instantâneas (Benveniste, 2005, p. 267).

Weinrich (1973) retoma o trabalho de Benveniste (2005), considerando também dois planos: o do relato ou da narração ("erzählte Welt", em alemão), que equivaleria ao "plano histórico", nos termos de Benveniste, e o do debate ou comentário ("besprochene Welt"), que seria o "plano discursivo", nos termos de Benveniste.

Para estes autores, seriam duas atitudes de locução. Uma diria respeito ao "mundo objeto de relato/narrativa", isto é, um convite a entender o que é dito de maneira mais "relaxada" ou distante, já que a intervenção do ouvinte não é imediatamente solicitada; e outra seria a do "mundo objeto de debate/comentário", em que o que é dito deve ser interpretado como algo a reagir mais imediatamente.

É importante ressaltar que, para essa análise, deve-se ir além da constatação do tempo como categoria, mas se deve interpretá-lo. Nas palavras de Weinrich, sobre os tempos verbais:

Conforme eles indicam comentário ou narrativa, eles transformam a situação de comunicação, e essa mudança de orientação é, para o ouvinte, de uma pertinência extrema. Esse não seria o caso se eles somente fornecessem informações relativas ao tipo de situação ou ao gênero literário. A razão de sua ancoragem profunda no processo de comunicação deve estar em outro lugar. Essa 'obstinação' dos morfemas temporais em indicar comentário e narrativa permite que o locutor influencie o ouvinte, modele a recepção que ele deseja para seu texto. Ao empregar os tempos comentativos, eu informo meu interlocutor que o texto merece uma atenção vigilante de sua parte. Por meio dos tempos da narração, pelo contrário, eu o advirto que uma outra escuta, mais desapegada, é possível. É esta oposição entre o grupo de tempos do mundo narrado e o de tempos do mundo comentado que eu caracterizarei como atitude de locução (deve ser entendida como aquela em que o locutor pede do ouvinte uma reação correspondente, de modo que a atitude de comunicação criada lhes seja comum) (WEINRICH, 1973, p. 30).

Para Weinrich (1973), o passado empregado no mundo do comentário engaja, é uma carga. Já o futuro, que ele promete ou ameaça, exige que nos preocupemos com ele. É o mundo cuja existência nos obriga. No mundo narrado, por outro lado, as manifestações são mais livres, no sentido de que asseguram a "liberdade do narrador", que está seguro sobre o fim e controla o fluxo do relato, podendo retardar ou antecipar 
à vontade o seu curso, por vias retrospectivas ou predições. O tempo não tem, sob esta perspectiva, uma função de indicar um evento no passado ou no futuro, mas uma função discursiva, de indicar um tipo textual.

Pelo que compreendemos, numa leitura ainda bastante inicial dos trabalhos dos dois autores, no que diz respeito a uma sugestão de análise de textos, enquanto a reflexão de Benveniste explica muito bem o intuito do historiador, a de Weinrich é interessantíssima para interpretar obras literárias, como os romances.

As possíveis implicações e críticas das propostas de Benveniste e Weinrich para uma compreensão do funcionamento dos planos enunciativos dos textos, incluindo um estudo dos sistemas temporais do português, é assunto para um próximo artigo.

\section{Considerações finais}

A contribuição de Benveniste (2005), conforme podemos constatar ao fim deste trabalho, é a de pensar a dêixis como importante fenômeno enunciativo, de como a marca de pessoa institui e instancia o discurso de modo a permitir o exercício da linguagem. Não se trata do fenômeno de apontamento para os referentes que decorre do processo referencial, mas daquilo que permite aos interlocutores entender como o que é referido se relaciona com os participantes da situação discursiva. Nessa visada enunciativa, a dêixis não deixa de apresentar um caráter sinalizador, contudo, essa sinalização é feita relacionando os enunciados à presente instância do discurso. É uma visão bastante restritiva sobre a dêixis, mas que oferece a vantagem de distinguir esses elementos tão especiais que as línguas fornecem. Além disso, propicia uma explicação sobre recursos fundamentais para o funcionamento da língua.

Já Bühler (1934) defende uma noção de dêixis como fenômeno de ostensão a objetos em situações comunicativas e apresenta diferentes modos dêiticos, de acordo com os campos de percepção humana. Tal abordagem é propícia para o desenvolvimento dos estudos de processos referenciais em situações comunicativas, incluindo a questão 
dos critérios para as tipologias. A vantagem dessa abordagem está na possibilidade de análise da construção do sentido dos textos. Além disso, essa abordagem pode contemplar sinalizações não-verbais, integrantes das interações comunicativas humanas, o que abre toda uma outra janela de análise, incluindo as abordagens socio e etnocêntricas da dêixis.

Sobre a questão do título do artigo, não sugerimos, portanto, uma escolha definitiva, entre a dêixis como fenômeno enunciativo ou referencial, mas assinalamos a importância de aprofundarmos a reflexão dos autores que trataram do assunto. E, afora a questão terminológica, sempre bastante problemática na linguística, em especial entre as diferentes abordagens, deixamos a sugestão de que é sempre bem-vindo o esclarecimento sobre os princípios teóricos em que fundamentamos o nosso trabalho de pesquisa.

Por fim, entre Weinrich (1973) e Benveniste (2005), vislumbra-se uma possibilidade de análise de tipos de embrayeurs textuais, que orientam, especialmente pelo viés do tempo relacionado à marca de pessoa, o modo como os textos podem ou devem ser interpretados.

Sobre esse último eixo, de antemão, apontamos para a necessidade de repensar a proposta para os tempos verbais do português (e de outras línguas, além do francês). E, além disso, prospectamos um estudo dos textos do gênero acadêmico, sob essa perspectiva, que pode ser interessante, especialmente se pensamos no ensino de escrita acadêmica.

\section{Referências}

BENVENISTE, Emile. Problemas de Linguística Geral, I. Campinas: Pontes, 2005.

BÜHLER, Karl. Sprachtheorie: Die Darstellungsfunktion der Sprache. Jena: Fischer, 1934. 
CAVALCANTE, Mônica Magalhães. Expressões indiciais em contextos de uso: por uma caracterização dos dêiticos discursivos. 2000. 204 f. Tese (Doutorado em Lingüística) Universidade Federal de Pernambuco, Recife.

- CIULLA, Alena. Os processos de referência e suas funções discursivas: o universo literário dos contos. Tese. 201p. Doutorado em Linguística. Fortaleza: Universidade Federal do Ceará, 2008. [15 de novembro de 2014] <http://www.repositorio.ufc.br/handle/riufc/3615>.

CIULLA, Alena. Sobre a noção de dêixis e critérios de tipologias dêiticas. Anais do I JOLINT - Jornada de Linguística Textual - diálogos em Estudos da Linguagem. FARIA, Maria da Graça dos Santos et al. (orgs.) 2019, p. 419-429.

CIULLA, Alena. A referenciação anafórica e dêitica - com atenção especial para os dêiticos discursivos. 2002. 90 f. Dissertação (Mestrado em Linguística) - Universidade Federal do Ceará, Fortaleza.

CIULLA, Alena e MARTINS, Mayara. Um estudo sobre classificação de tipos dêiticos. Universidade Federal do Ceará, Fortaleza, Revista de Letras, vol.2, n. 36, jul./dez. 2017, p.78

JUNGBLUTH, Konstanze; DA MILANO, Federica. Manual of Deixis in Romance Languages. Berlin/Boston: De Gruyter, 2015.

KLEIBER, Georges. Dêiticos, embreadores, 'token-reflexivos', símbolos indexicais etc.: como defini-los?. Trad. Mayalu Félix. Intersecções, ed. 11, Ano 6, n. 3, p. 2, nov. 2013. MARTINS, Mayara. A caracterização dos tipos de dêixis como processos referenciais. 2019. 142 f. Dissertação (Mestrado em Linguística) - Universidade Federal do Ceará, Fortaleza.

QUINE, Willard van Orman. Word and Object. New York/London: John Wiley \& Sons Inc., 1960.

WEINRICH, Harald. Le temps : le récit et et le commentaire. Paris : Seuil,1973, p. 9-3o.

Recebido em 06/03/2020. Aprovado em 14/o7/2020. 